\title{
educação

\section{Revezamentos entre teoria e prática: Movimentos que acionam outros modos de pensar o ensino da arte}

\author{
Marilda Oliveira de Oliveira', Vivien Kelling Cardonetti ${ }^{\mathrm{II}}$ \\ $\&$ Cláudia Aparecida dos Santos ${ }^{\text {III }}$ \\ Universidade Federal de Santa Maria, Brasil
}

\author{
Francieli Regina Garlet ${ }^{\text {IV }}$ \\ Universidade Estadual de Maringá, Brasil
}

\begin{abstract}
Este texto abordará algumas experimentações que temos realizado no Ensino Superior com as turmas de graduação e também com turmas de pós-graduação. Nosso desafio tem sido: como fazer um revezamento entre teoria e prática de maneira a que essas instâncias não aconteçam de formas separadas? Para tanto, temos procurado sobrepô-las de modo a que aconteçam concomitantemente. Essas experimentações têm se dado na forma de elaborar os projetos de estágio e nas próprias aulas de estágio curricular supervisionado, onde os professores em formação assumem uma turma na escola ou em outro espaço educativo. Igualmente no que se refere aos procedimentos de fazer pesquisa, procura-se que a dissertação e a tese também sejam operadas a partir deste revezamento e concomitância. Para a realização desta escrita empreendeu-se um estudo teórico-conceitual de cunho bibliográfico em autores filiados nas bases teóricas das filosofias da diferença. Desse modo, buscou-se a despersonalização dos autores para falar de uma vida que é escrita por atravessamentos e encontros, ou seja, pensar a vida como a própria elaboração do texto, uma escrita biografemática, seguindo a proposta de Roland Barthes. Assim fomos compondo, com o vivido, com as leituras, as falas nos encontros e as visualidades, os apontamentos, e a partir dessa materialidade é que ensaiamos esse texto.
\end{abstract}

Palavras-chave: Filosofias da diferença; Ensino da arte; Biografemática; Educação

\section{UM BREVE SOBREVOO}

A elaboração do presente artigo partiu da ideia de pensarmos sobre o que temos experienciado em espaços educativos de graduação e pósgraduação, dos desafios diários em operar um revezamento entre teoria e prática, de modo a arrastar concepções que descansam ou capturam o corpo/pensamento educativo e que insistem em se infiltrar nos discursos que ouvimos por aí: 'Na teoria é uma coisa, na prática é outra...' Nos colocamos a pensar por que essa afirmativa é tão presente nos discursos docentes e dos que se aventuram nesse território, e cogitamos 
algumas possibilidades: uma delas pode ser o fato de esperarmos que algumas teorias nos digam 'o que fazer', nos deem uma fórmula que não produza equívocos ao operarmos com elas. Dessa forma se produz um hiato entre o que a teoria propunha e os resultados inesperados que se produzem com ela. E se nosso posicionamento quanto a esse hiato, muitas vezes, é de pensá-lo como uma falta, ou falha, ou impossibilidade de a teoria se encaixar com a prática, perdemos a chance de saltar nesse hiato, de experimentá-lo, de perceber a potência de sua impossibilidade de ajuste, perdemos a chance de operar a teoria, fazendo-a cintilar em suas variações.

Outro motivo de tal recorrência nos parece ser que, muitas vezes, esperamos que a teoria venha a nos explicar os porquês de certas coisas acontecerem, e apostamos nas teorias como explicações inequívocas do mundo, como verdades vindas de pessoas quase que divinas, de tão legitimadas a falarem sobre o que nos passa, e aí novamente ocorrem desajustes, pois as realidades, além de múltiplas, estão a todo o momento se movimentando e se produzindo, implorando para si outros modos de serem escritas/pensadas.

Perdemos, nesse caso, a chance de 'conversar' com a escrita/fala do autor - a qual é também composta de uma multiplicidade, pois, como afirma Deleuze, no livro Microfísica do Poder, de Michel Foucault (2012), quem fala e age "é sempre uma multiplicidade, mesmo que seja na pessoa que fala ou age. Nós somos todos pequenos grupos" (p. 70). Conversar diz respeito, portanto, a uma escuta e produção de sentidos que se dão em um 'entre', que não se fixa no que o autor disse nem na imposição de encaixe de nossas experiências com o que ele disse. Uma conversa, no modo como a entendemos aqui, existe no desajuste, e não propriamente na busca de um consenso apaziguador; trata-se de aliança que arrasta um e outro a ser diferente do que é.

Talvez esse desajuste seja a potência ou ponto de encontro ${ }^{1}$ entre teoria e prática, o que faz uma arrastar a outra a regiões desconhecidas que as fazem fulgurar em outras possibilidades de existência, a produzirem-se a partir da diferença.

\section{REVEZAMENTOS ENTRE TEORIA E} P R Á T I C A

Deleuze, em diálogo com Foucault no livro Microfísica do Poder (2012), menciona:

Às vezes se concebia a prática como uma aplicação da teoria, como uma consequência; às vezes, ao contrário, como devendo inspirar a teoria, como sendo ela própria criadora com relação a uma forma futura de teoria. De qualquer modo, se concebiam suas relações como um processo de totalização, em um sentido ou em um outro. Talvez para nós a questão se coloque de outra maneira. As relações teoria-prática são muito mais parciais e fragmentárias. Por um lado, uma teoria é sempre local, relativa a um pequeno domínio e pode se aplicar a um outro domínio, mais ou menos afastado. A relação de aplicação nunca é de semelhança. ... A prática é um conjunto de revezamentos de uma teoria a outra e a teoria um revezamento de uma prática a outra. Nenhuma teoria pode se desenvolver sem encontrar uma espécie de muro e é preciso a prática para atravessar o muro. (pp. 69-70)

Desse modo, não se pensa a teoria e a prática como representação ou decalque uma da outra; teoria e prática acontecem no fluxo de um revezamento que potencializa, que faz tomar fôlego, uma e outra. Operar teoria-prática implica 'obrar', atravessar muros que encontramos

\footnotetext{
${ }^{1}$ Encontro como duplo-roubo ou dupla-captura. Como menciona Deleuze e Parnet (1998), “encontrar é achar, é capturar, é roubar, mas não há método para achar, nada além de uma longa preparação. Roubar é o contrário de plagiar, de copiar, de imitar ou de fazer como. A captura é sempre uma dupla-captura, o roubo, um duplo-roubo, e é isso que faz, não algo de mútuo, mas um bloco assimétrico, uma evolução a-paralela, núpcias, sempre 'fora' e 'entre'. Seria isso, pois, uma conversa' (p. 15).
} 
(inventamos?) em meio ao percurso, implica criar impossibilidades e ao mesmo tempo um possível (Deleuze, 1992). Trata-se, pois, da 'invenção de problemas' (Kastrup, 2005), ao mesmo tempo em que se afirma a precariedade de nossos próprios discursos.

Afirmar tal precariedade implica estar atento ao que se agita a partir das verdades que produzimos, entendendo essas verdades como cascas provisórias que não aguentarão por muito tempo, pois a teoria nunca dá conta da prática e a prática nunca dá conta da teoria, já que ambas estão constantemente sendo produzidas nesse revezamento, sempre em obra, em curso.

Assim, nossa formulação indica que este modo de operar por revezamento expressa relação de tensionamento e deserção, flexuosidade que corre, não de cima para baixo ou de baixo para cima, mas que transborda para os lados; o que vaza dessa esfera teórico-prática como um possível afronta a fixidez das relações de poder que estratificam modos de agir $\mathrm{e}$ produzir conhecimento na educação. Movemonos lateralmente entre teoria e prática num serpentear que não repousa, sempre em trânsito. Sob este revezamento, se complexifica a relação hierárquica da teoria com a prática, ao romper, ou, ao menos, borrar, algumas delimitações de barreiras que se erguem entre elas, de forma que não se trata de uma apologia de uma ou de outra, mas da potencialização de ambas, no abalo de uma das dicotomias que sedimenta na educação.

Como menciona Deleuze (2009), "a teoria não totaliza; a teoria se multiplica e multiplica” (p. 71). A partir da perspectiva anunciada, entendemos que toda teoria que penetra em um determinado ponto choca-se com a impossibilidade de seu espelhamento, pois é sempre forma que precisa funcionar a cada vez; por este motivo, a noção de aplicação de uma teoria nos parece inadequada frente à multiplicidade que a ela se impõe, uma vez que falar pelos outros é sempre um modo de impor uma identidade que se quer comprovar.

\section{Possíveis ENTRECRUZAMENTOS COM OS CONCEITOS DE ESPAÇO LISO E ESPAÇO ESTRIADO}

Podemos estabelecer um diálogo entre esse revezamento (teoria-prática) e o que Deleuze e Guattari (2012) definem como espaço liso e espaço estriado, uma vez que verdades injetadas no cotidiano também podem, neste contexto, ser mobilizadas e colocadas sob suspeita. É com relação ao pensamento que os autores operam esses conceitos, pois segundo eles há uma imagem do pensamento que implica determinados modos estruturados de pensar, a partir de uma certa organização a priori, mas há também um pensamento sem imagem que apenas acontece, em seu próprio fluxo, forçado por um disparador inicial, mas sem obedecer a um modelo prévio do que seja pensar. Assim, o espaço liso, segundo os autores, seria esse espaço nômade onde o pensamento ganha velocidade. Já o espaço estriado, seria um espaço sedentário, onde o pensamento se dá a partir de uma organização.

Topologicamente o espaço liso se constrói como campo aberto de contínua variação (intensidades). Por sua vez, o espaço estriado refere-se a um sistema fixo e localizável (trajetos). Numa primeira vista, corre-se o risco de esta distinção entre espaço liso e espaço estriado se dar como uma forma de oposição simples; por isso sublinha-se que, a partir de Deleuze e Guattari (2012), o espaço estriado e liso "existe de fato graças às misturas entre si” (p. 192), o que não impede sua distinção.

Mais que uma proposição geográfica, aqui

\footnotetext{
${ }^{2}$ Segundo Kastrup (2005), “a invenção não se confunde com a criatividade. Os estudos acerca da criatividade, iniciados nos EUA por J. P. Guilford e que ganharam força sobretudo na década de 1960, definem a criatividade como uma capacidade de produzir soluções originais para os problemas. Mas a invenção de que eu falo, e para isso me baseio na filosofia de G. Deleuze (1988), não é uma capacidade de solução de problemas, mas, sobretudo, de invenção de problemas" (p. 1274).
} 
operamos com esses conceitos para pensar o espaço e o território da educação, enquanto atuação em sala de aula e movimento na produção de pesquisas. Compreendemos estes espaços (liso e estriado) como processos de provocação mútuos, jogo intensivo em que, se um é condição de alisamento espacial, o outro é passível de estriação. Embora apresentem uma diferença de natureza, estes dois espaços não param de se provocar um ao outro, de se produzir um ao outro. Estão, pois, em pressuposição recíproca. Os movimentos pelos quais esses espaços buscam se manter são diferentes: enquanto o espaço estriado busca capturar o liso, freando-o, colocando-o em ordem, o espaço liso busca se diluir no espaço estriado, procurando fendas para vazar e para desterritorializá-lo. O espaço liso ou nômade é marcado apenas por traços que se apagam e se deslocam com o trajeto. Ele se insinua 'entre' os espaços estriados, que tentam limitá-lo refreando seu desenvolvimento. É sobre o espaço estriado que o espaço liso se volta contra, buscando vazar e transbordar.

A partir desses conceitos de espaço liso e espaço estriado, nos colocamos a pensar que operar uma teoria (enquanto prática) seria, talvez, um modo de alisar o espaço estriado, que ela mesma (a teoria) organiza enquanto arquivo ${ }^{3}$, provisoriamente; operar uma teoria seria, talvez, inventar modos singulares de deslocamento, fluidos, que possam passar entre uma região e outra (do que já foi dito, teorizado) arrastando essas produções de outrora para outros modos de existência; esse ato operatório do espaço liso (prática) poderia, quem sabe, inventar - com o espaço estriado do que já foi dito (teoria) - regiões outras ainda por vir.

Pensar um revezamento entre teoria e prática implicaria pensar nessas provocações entre espaço liso (prática) e espaço estriado (teoria). O espaço liso é aquele que abriga uma experimentação singular de pensamento, que acaba por arrastar as bordas da razão, produzidas por um espaço estriado, para o estiramento de uma problemática imanente, que se ensaia na própria errância do pensamento, num espaço desconhecido, sem pontos de referência, nem destino projetado a priori.

Este revezamento enquanto operação espacial, que por vezes territorializa e por vezes faz fugir, resulta de práticas concretas, isto é, de modos de atuar frente à suposta linearidade dos trajetos, imbricados nas relações que produzimos, nos limites que se erguem entre a verdade e a aparência, entre a ordem e o caos, entre a teoria e a prática, em que se busca dar visibilidade aos estilhaços que nos constituem, lá mesmo onde não há mais identidade, onde o eu se encontra dissipado na multiplicidade que o concebeu.

Apostamos na alternância, engendrada enquanto modo de equilíbrio frente à degeneração das formas de conhecer e produzir conhecimento. Essa degeneração cultural iniciada pelo pensamento socrático-platônico aguça-se, como denunciado por Nietzsche (1998), com o advento do cristianismo (deus unificado) e, posteriormente, com o cientificismo e as teorias positivistas, na racionalização sistematizada como pressuposto único para a compreensão do mundo ${ }^{4}$. Traçar entre a teoria (epistemologia) e a prática (empiria) linhas para um deslocamento desejável, tendo em vista que cada um destes

\footnotetext{
${ }^{3}$ A noção de arquivo é entendida aqui a partir de Foucault (1997): "É, de início, a lei do que pode ser dito, o sistema que rege o aparecimento dos enunciados como acontecimentos singulares" (p. 149). É o sistema que determina que enunciados permanecerão em cena e quais desaparecerão. Assim sendo, é um estrato, uma lei, composta de saberes (enunciados e visibilidades). Estrato do que é possível ver e dizer em determinada época.

${ }^{4}$ Vejamos o que Deleuze (2009) tem a dizer sobre essa questão: "A degenerescência da filosofia aparece claramente com Sócrates. Se definimos a metafísica pela distinção de dois mundos, pela oposição da essência e da aparência, do verdadeiro e do falso, do inteligível e do sensível, é preciso dizer que Sócrates inventou a metafísica: ele faz da vida qualquer coisa que deva ser julgada, medida, limitada, e do pensamento, uma medida, um limite, que exerce em nome dos valores” (p. 20).
} 
campos opera sob condições próprias, que não são equivalentes nem redutíveis entre si, ajusta-se a um plano experimental, uma vez que entende o pensamento numa vertente ininterrupta, porém não fácil ou gratuita, mas que requer auto superação e transgressão.

Pensar é uma prática infinita, acionada antes mesmo de tomar uma possível forma. Antes da forma, o que existe é o informe, o pensamento errante a vagar em velocidades e lentidões, a experienciar um espaço liso, onde vai cartografando regiões ao passo que as produz. Mas, muitas vezes, colocamos as formas como primeiras, e aí corremos o risco de entendêlas como verdades petrificadas, impossíveis de quebrar, o que acaba por nos petrificar em camadas duras também.

Cabe aqui mencionar um trecho do que Tony Hara (2012) expõe no ensaio A Errância e o Mar de Mil Caminhos, ao se referir ao pensamento de Foucault no livro História da Loucura:

O que se procura nessa obra memorável é justamente a abertura, a possibilidade de um diálogo entre a razão e a desrazão, uma certa unidade tensa, ou se preferir, trágica, entre as verdades petrificantes laboriosamente esculpidas pelo cinzel da razão e as verdades vaporosas que chegam dançando no dorso das ondas e que desvanecem por obra do acaso. (p. 35)

O arrolamento entre razão e desrazão compõe o cerne de uma perspectiva adotada por Foucault no início da década de 60, na formulação de um saber sobre a loucura no Ocidente. Como anuncia Hara (2012), buscou-se, neste estudo, uma abertura implicada no trânsito dos discursos em que se produzem as verdades, animadas por jogos de poder. Na obra citada, nota-se a crítica à racionalidade pura, enquanto modelo que constrói sua identidade através da exclusão do outro, neste caso "a desrazão".

Uma vez que se entende o pensamento como uma estrutura aberta, intensiva, nota-se que o conhecimento estratificado atua simplificando; portanto, generalizando em categorias fechadas uma multiplicidade de realidades que sempre escapam. As categorias lógicas, os espaços estriados acabam por expressar, não nossas experiências singulares, mas o desejo de verdade. Nosso objetivo ao cunhar tais aproximações é propiciar (ao menos para nós) um trânsito acerca das possibilidades e impossibilidades de variar como forma de conhecer, menos disciplinares, mais permissivas, a partir do disforme (Oliveira, 2015), e que não se deem tão atreladas às tradicionais experiências no campo educacional. Neste aspecto, este revezamento, esta variação, compõe uma espécie de anormalidade que pode ser assumida como forma de resistência, como nos sugere Boutang (1988-1989).

Percebemos assim, na tensão do par razão e desrazão, uma relação intrínseca em que se arquitetam os saberes e que permite traçar alguns degradês de uma pretensa linha mediana. $\mathrm{Na}$ promoção de uma conversa que vai até o limite extremo do que pode uma e outra a cada vez, entre o que se explica (trajetos) e o que se sente (intensidades), e suas partilhas, das quais não se tem como escapar.

E a ideia de 'conversa' surge, novamente, como uma 'unidade tensa', e não como calmaria. Uma conversa entre espaço liso e espaço estriado, entre teoria e prática, entre as verdades produzidas pelas teorias e as verdades vaporosas que se produzem e dançam em meio às experimentações singulares do nosso corpo/pensamento, as quais deixam no ar algumas questões: Que vapores se erguem do que lemos? Como essas leituras afetam nosso corpo/pensamento? Como atravessam nossas atuações, nossos modos de vida? De que modo podemos produzir uma relação potente com a leitura, com a teoria, abrindo-nos a possíveis encontros, ao que elas podem disparar em nosso corpo/pensamento?

Larrosa (2011) faz algumas provocações nesse 
sentido, instigando a pensar nossas experiências com a leitura.

Quando eu leio Kafka (ou qualquer outro), o importante, desde o ponto de vista da experiência, não é nem o que Kafka pensa, nem o que eu possa pensar sobre Kafka, mas o modo como, em relação com os pensamentos de Kafka, posso formar ou transformar meus próprios pensamentos. $\mathrm{O}$ importante, desde o ponto de vista da experiência, é como a leitura de Kafka (ou de qualquer outro) pode ajudar-me a pensar o que ainda não sei pensar, ou o que ainda não posso pensar, ou o que ainda não quero pensar. O importante, desde o ponto de vista da experiência, é que a leitura de Kafka (ou de qualquer outro) pode ajudar-me a formar ou a transformar meu próprio pensamento, a pensar por mim mesmo, em primeira pessoa, com minhas próprias ideias. (p. 11)

Transformar o próprio pensamento, pensar o que ainda não se sabe pensar, pensar em primeira pessoa... Tais fragmentos remetem às nossas tentativas em meio às nossas experiências educativas e de pesquisa, que na verdade não possuem, elas também, limites claros, pois uma adentra a outra, uma impulsiona a outra, uma produz a outra. Tentamos escapar dos modos naturalizados, uma vez que nos apressamos em dizer que não sabemos "o que significa uma verdade objetiva, todas as verdades são" para nós "verdades sangrentas", posto que "não somos aparelhos de objetivar e registrar, de entranhas congeladas - temos de continuamente parir nossos pensamentos" (Nietzsche, 2001, p. 12).

A estratégia apresentada requer (uma vez que não se pretende provar o que se pensa, diz e escreve) ser compreendida em sua relação de resistência às heranças do paradigma moderno, em que os objetos de pesquisa têm sua validade somente mediante comprovação. Vemos aí o risco de acreditar que nossas pesquisas retratam uma realidade, ou que alcançam o que outras não podem. O revezamento que propomos tira-nos a cada instante as certezas produzidas, colocandoas para conversar.

Buscamos, assim, perder o caráter de filiação para com as teorias do conhecimento que esboçam uma relação hierárquica e de adequação com o mundo a ser conhecido. Apostamos no que se arquiteta entre, no revezamento entre um e outro, justamente por entendermos o conhecimento, e sua correlata produção, sempre como uma disputa. À volta de todo o conhecimento existem lutas, e não natureza fixa. Em que pese que a existência da verdade não se encontra na decifração dos véus que camuflam sua face, mas num conjunto de procedimentos metodológicos e institucionais precários e provisórios que determinam a produção de uma verdade e não de outra 5 .

Investimos na possibilidade do diálogo entre os espaços da educação, cingindo um princípio plástico inseparável daquilo que fundamenta a produção de um pensamento que se metamorfoseia pelas forças que o impulsionam. Em meio a fragmentos de escritos que nos afetam e composições com imagens e escritas, temos nos aventurado a experienciar um revezamento entre teoria e prática de um modo singular, que implica nos lançarmos em corpo/ pensamento nessa experimentação. Pensamos, escrevemos, compomo-nos nesse processo. Temos buscado alisar espaços teóricos e modos estriados de relação com a teoria; o próprio território teórico é quem, muitas vezes, funciona como mar, esse espaço liso por excelência, ou, ainda, é ele quem nos atira em um mar liso sem pontos de referência, sem destino, no qual nosso corpo/pensamento é impelido a movimentar-se,

\footnotetext{
${ }^{5}$ Concordamos com Nietzsche (1998) quando refere: "Existe apenas uma visão perspectiva, apenas um conhecer perspectivo, e quanto mais afetos permitimos falar sobre uma coisa, quanto mais olhos, diferentes olhos, soubermos utilizar para essa coisa, tanto mais completo será nosso conceito dela” (p. 109).
} 
praticar-se, produzir-se singularmente a partir desse encontro/relação.

O modo como pensamos metodologicamente este texto foi a partir de biografemas, ou seja, a partir do método da biografemática. Modo como tem sido tratado, no campo da pesquisa, este método idealizado por Barthes, publicado em francês em 1975 e no Brasil em 2003 no livro Roland Barthes por Roland Barthes. Trata-se de um modo de fazer pesquisa a partir da forma como se escreve sobre a vida e o que nos acontece. Trata-se de despersonalizar os autores para falar de uma vida que é escrita por atravessamentos e encontros, ou seja, pensar a vida como a própria elaboração do texto.

\section{SOBRE TRANSITAR 'ENTRE' PESQUISA E DOCENCIA E INVENTAR TENSIONAMENTOS ENTRE TEORIA E P R Á T I C A}

Pesquisa e prática docente, dois terrenos de fronteiras não tão nítidas, que podem imiscuirse um no outro e movimentar um revezamento/ tensionamento entre teoria e prática. Pensamos, nesse trecho do caminhar dessa escrita, em dois pontos de força: a 'docência como zona de pesquisa' (Mossi, 2016) e a noção de 'professorpesquisador' (Corazza, 2013).

Quando Mossi (2016) se refere a 'docência como zona de pesquisa, o autor aposta em uma prática docente que se distancia de fórmulas prontas e de modelos estanques. As aulas passam a ser ambientes para a invenção de problemas (Kastrup, 2005) que instigam o pensar, diferindo da mera solução de problemas dados, que acaba limitando multiplicidades. Dessa forma, a pesquisa passa a desafiar professores e estudantes a estarem sempre em movimento, em linhas de errância (Deligny, 2015) por espaços lisos e estriados. O espaço/tempo da aula pode se configurar, assim, como lugar onde podemos permanecer à espreita de encontros.
Deleuze menciona, na entrevista concedida à jornalista Claire Parnet (Boutang, 1988-1989), que os encontros não são programados para acontecer, e por isso temos que estar à espreita, tal como um animal que está sempre atento ao que acontece à sua volta. Deleuze visitava com frequência exposições de arte e ia ao cinema, mas não frequentava estes locais em busca de saberes e informações; o fazia, sim, para ficar à espreita de encontros, um esforço para ter a possibilidade de ter encontros com ideias, com algo que o afetasse, o perturbasse e violentasse seu pensamento a pensar, a andarilhar num processo de invenção.

Se virmos nossos encontros com a teoria, com as leituras, pensando-as como inseparáveis de uma prática de pensamento, também podemos pensá-las como esse espaço/tempo de espreita, onde nosso encontro com elas é que vai definir o que elas podem, e o que podemos com elas.

A invenção, não se configurando como uma busca dirigida, tampouco pode ser pensada como uma simples espera. É necessário muito trabalho para ter a possibilidade de que ela aconteça. A invenção não está sujeita a previsibilidade, mas também não é um ato espontâneo, exige tempo e esforço (Kastrup, 2007). Esforço, pois experimentamos outros caminhos que não aqueles já abertos pelo hábito e que, por isso mesmo, seriam mais fáceis de trilhar. Tempo, para que tenhamos a oportunidade de experienciar, em meio ao percurso, outros encontros que não imaginávamos de antemão, elementos inesperados que podem reorientar todo o processo.

Em sua investigação, Mossi (2016) tem buscado problematizar o que pode haver de criação em docências atravessadas pela arte e pela pesquisa e o que pode haver de pedagógico em produções que se querem artísticas, as quais, assim como a docência, envolvem um trabalho de investigação. Trata-se de colocar sob suspeita essas figuras identitárias e apostar nos 
borramentos dessas fronteiras, nas conexões e nos compartilhamentos realizados entre a arte, a docência e a pesquisa (Mossi, 2016).

No projeto de pesquisa que Cristian Poletti Mossi desenvolve na Universidade Federal do Rio Grande do Sul (UFRGS), intitulado 'Laboratório de Produção de Docências: Pesquisa e Criação em Educação das Artes Visuais', o autor tem procurado olhar para as aulas de licenciatura como laboratórios, visando investigar que possíveis vínculos podem ser estabelecidos entre produção artística, formação docente e pesquisa em educação das artes visuais, em meio a visualidades, leituras e escritas de professores em formação. Esse projeto tem investido na ideia de uma docência inseparável da pesquisa, que busca se singularizar em vez de se adequar a figuras já prontas de ser professor, o que implica também um revezamento de teoria e prática. Podemos entender o próprio ato de pesquisar como esse revezamento, como essa constante movimentação entre produção de espaços lisos e estriados, que ora produzem/definem contornos (estriando provisoriamente o espaço), ora são arrastados em velocidade pelas potências dos encontros que borram as bordas antes delimitadas.

Nesse viés, a prática docente no ensino de artes visuais atrelada à pesquisa passaria a compartilhar e a compor saberes, experimentações, questionamentos, dúvidas, equívocos e acertos. Esse trânsito entre arte, docência e pesquisa soa favorável a contribuir para a criação de algo 'outro', distanciando-se tão somente da reprodução de saberes apreendidos ou do desvelamento de alguma realidade escondida. Nessa imbricação, torna-se, por vezes, impossível reconhecer onde começa uma e termina a outra.

Essa zona de criação contribui para uma invenção constante do docente, que investiga suas práticas e suas inquietudes junto com os estudantes. Essa postura investigativa do professor passa a respingar nos estudantes, que, a partir das aulas, das atividades propostas e das produções escritas, começam a ser instigados a se inventar nesse processo. O professor, ao criar sua aula, também vai se criando nesse percurso. Dissolve-se nessas ações, reinventando-se a todo instante.

A docência sem pesquisa não existe, tampouco existiu ou existirá. Essa afirmação de Corazza (2013) abre as discussões para o segundo ponto de força. A autora discorre sobre a questão do professor-pesquisador que apresenta um espírito investigativo, pois, enquanto educa, entra em devires-pesquisadores, estando atento a seus movimentos em relação às suas problemáticas profissionais e às suas experimentações de criações pedagógicas, estriando, escrevendose, pensando-se, e, ao mesmo tempo, sendo provocado a lançar-se em um espaço liso; no revezamento desses espaços, nos quais experimenta velocidades e lentidões, pode inventar um modo singular de estar docente.

O ensino-pesquisa é uma invenção, visto que não representa ou reforça o que foi sistematizado anteriormente. Sua contribuição é interromper a mesmice da formação docente que assegura a permanência das supostas formas universais do pensamento sobre como ser professor.

$\mathrm{O}$ pensamento educacional que se tece aqui, envolto por multiplicidades, implica um estado de abertura e atenção à diferença como valor fundante do mundo da vida. Em que despontam, igualmente válidas, as formas tradicionais do conhecimento, outras possíveis direções. Compreendemos, assim, a produção de conhecimentos diretamente ligada à ideia de movimento e potencialização da vida. A partir dessa perspectiva nos valemos da variação entre os planos liso e estriado para pensar a educação, tendo em vista a natureza do deslocamento que leva de um a outro, capaz de gerar desterritorializações e reterritorializações constantes que podem perpassar as estruturas postas, ou ainda resistir a elas. 
Tal traço vem potencializando a compreensão imanente ao ensino-pesquisa, uma vez que não nos cabe perguntar o que determinada coisa é, mas com o que ela se encontra e em que ponto de tensão desterritorializa. Corazza (2013), neste sentido, explicita que os piores inimigos para o ensino-pesquisa são os manuais de autoajuda, em que são oferecidas receitas de como dar uma boa aula, desenvolver um ótimo currículo, formas eficazes de ensinar ou maneiras de ser um professor criativo. $\mathrm{O}$ ensino-pesquisa abandona todo e qualquer anseio à universalização e uniformidade de seus resultados. Essa atitude investigativa do professor, em contrapartida, irá exigir um nível de tolerância à frustação, pois a incerteza, a imprevisibilidade e a transgressão estarão à espreita lado a lado em seu percurso.

$\mathrm{O}$ intuito de produzir um pensamento educacional pela diferença nosleva ao exercício de perspectivar a elaboração de projetos de ensinopesquisa versáteis como forma de potencializar a produção dos conhecimentos, quer seja do estudante, quer seja do professor. O revezamento que propomos entre teoria e prática, a nosso ver, tende a desconstruir rótulos e vícios de linguagem e ação, agindo no que está estabelecido como terreno de atuação. E o fazemos como uma forma de devir, que se encontra sempre no 'entre', vazando e arrastando o estático e os modelos. Podemos intuir, no decorrer deste processo, que é possível decompor espaços estriados em espaços de passagem, em que se permite ganhar maior velocidade. Por esta perspectiva, entrase em devir, em ações, em rupturas que lancem sempre a um outro ponto, para aquilo que ainda não habitamos, desafixando nossos próprios modos de ser docentes e pesquisadores.

Vale pontuar que o ensino-pesquisa consiste em criar soluções, mas também novos problemas, pois, a cada desafio, diferentes enigmas se produzem. Isso leva o professor a estar em processo constante de variação, levando-o a experienciar uma 'docência-pesquisa-que- cria' (Corazza, 2011). Nesse processo, ocorre a autocriação do professor, ou seja, um diferenciar, uma pura potencialidade de atualização, um produzir-se em alguém que não seja aquele que já é (Corazza, 2013).

\section{AlgumaS EXPERIMENTAÇões...}

Algumas experimentações têm sido realizadas no ambiente educativo-formativo no campo da Educação e Arte, tanto em disciplinas da graduação como nas da pós-graduação. A disciplina de Prática Educacional IV, do Curso de Graduação em Artes Visuais da Universidade Federal de Santa Maria, prevê a elaboração de um projeto de estágio que contemple ensino e pesquisa. Nessa disciplina, os acadêmicos têm condições de elaborar, durante todo o semestre, um projeto com uma problemática que, nos semestres seguintes, será proposta para os estudantes das escolas, onde irão desenvolver seus quatro semestres de Estágio Curricular Supervisionado.

A partir de um problema de pesquisa para investigar, e não apenas com a preocupação de ensinar, mas de aprender também com o grupo, o projeto de ensino e pesquisa é revisitado a cada semestre, pois no decorrer da prática dos estágios surgem questões para dar conta das exigências e demandas de cada diferente escola, sendo necessárias algumas mudanças, adaptações e acréscimos no corpo do mesmo.

Esta colocação reafirma a implicação da teoria e da prática, pois, devido à premência do momento, necessita-se rever e buscar outros conceitos para pensar o que está acontecendo. Gallo (2010), a partir dos estudos de Foucault, coloca que uma teoria faz sentido quando é operativa e permite a atuação daqueles que dela fazem uso. A teoria, nesse sentido, passa a ser uma ferramenta que produz circuitos instantâneos com as várias práticas, como também opera mudanças ou a construção de novas ferramentas teóricas. 
Em algumas situações, a teoria estudada nos projetos de estágio também faz com que o olhar fique mais atento e se direcione para determinadas coisas que talvez ficassem imperceptíveis se não houvesse o chamamento da teoria. É nesse revezamento entre espaço liso e estriado que teoria e prática vão se atualizando intensamente no decorrer da travessia. Como nos lembra Deleuze (2006), no livro A Ilha Deserta e Outros Textos: "ação de teoria, ação de prática em relações de revezamento ou rede" (p. 266). A partir dessas colocações podemos pensar que a docência é uma prática que está conectada à pesquisa, ao mesmo tempo que a pesquisa revitaliza e areja a docência. Em meio a essa rede, na qual vamos nos produzindo docentes e pesquisadores, teoria e prática vão sendo atualizadas, provocando movimentações, velocidades e lentidões.

Nas defesas dos Trabalhos de Conclusão de Curso (TCC), temos ouvido alguns depoimentos de futuros formandos relatando que a pesquisa que eles estão apresentando no final do curso começou na disciplina de Prática Educacional IV, no quarto semestre do curso, no projeto de estágio; foi naquele momento que foi semeada a 'pólvora' da pesquisa, sendo multiplicada a cada dia com a prática docente nos estágios. Assim também tem acontecido nas aulas dos estagiários, quando estes promovem exercícios visuais ou plásticos com os estudantes das escolas. Buscamos que este fazer não seja apenas um conteúdo procedimental, prático, mas que seja também conceitual, teórico. Eles têm exercitado este revezamento e concomitância.

Na pós-graduação com turmas de mestrado e doutorado temos buscado pensar a pesquisa com esses vieses: como a teoria tem operado com a materialidade, com a empiria? Como a empiria tem dialogado com os aspectos teóricos de uma dissertação ou tese?

Inferimos que estas questões têm nos acompanhado como gatilhos, uma vez que não há a busca de comprovar hipóteses, ou de formular respostas. As questões disparadas injetam ânimo para pensarmos/inventarmos outras relações com a pesquisa; em que as relações de composição do conhecimento se distanciem daquelas pré-concebidas, e se aliem às singularidades do pesquisar, suas provisoriedades e intencionalidades por arranjos menos pretensiosos.

\section{ESTRIAMENTOS PROVISÓRIOS QUE SE QUEREM NÔMADES...}

Faz-se oportuno pontuar neste momento, em que desejamos ir encaminhando este texto para uma finalização, que toda e qualquer teoria (ditos e vistos), longe de ser uma sentença final sobre como devemos agir/pensar, é antes invenção, experimentação que responde a certas urgências. Em cada teoria ou 'verdade' há um estriamento, uma estrutura composta de saberes e poderes, os quais abrigam a possibilidade de serem reforçados, mas também de serem desconstruídos.

Ao mensurar a verdade e seus desdobramentos para as ciências humanas e, consequentemente, para a educação, nota-se que aquilo qualificado como verdadeiro comumente tem arraigado a seu feitio a justificativa para a existência de uma certa identidade que se pretende afirmar. Aliás, o que é tornado possível sempre mediante a exclusão da diferença:

Fechado no navio, de onde não se escapa, o Louco é entregue ao rio de mil braços, ao mar de mil caminhos, a essa grande incerteza exterior a tudo. É um prisioneiro no meio da mais livre, da mais aberta das estradas: solidamente acorrentado à infinita encruzilhada. É o Passageiro por excelência, isto é, o prisioneiro da passagem. (Foucault, 1972, pp. 16-17) 
A dupla, razão e desrazão, volta mais uma vez a este texto, pois permite aproximar do campo educacional sua formulação axiológica e problematizar na educação o que ela deixa entrar e o que exclui, ou invisibiliza. $O$ texto foucaultiano diz do que é exilado, demonstra a situação liminar do louco no horizonte das inquietações do homem medieval. Em que o sujeito louco "é jogado no interior do exterior" (Foucault, 1972, p. 16). Pensamos, assim, esta relação como disparador para questionar os modelos de produzir ensino-pesquisa em nossas universidades, em cuja forçosa "navegação do louco" acontece ainda, e a cada vez que uma atuação "se opõe à estabilidade luminosa e adulta do espírito" (Foucault, 1972, p. 18).

Esta passagem capturada em Foucault expressa o horizonte cultural em que se inscreve a racionalidade, envolta por jogos de verdade, correlata à padronização dos modos e ao cumprimento dos modelos. Com a dogmatização ${ }^{6}$ do mundo moderno, produtora deobediência e renúncias, a excessiva planificação da educação, movida por um ideal positivista, levou-nos a alguns impasses. Cotidianamente, percebe-se uma asfixia em meio aos discursos pedagógicos hegemônicos. Daí a busca por novos ares para pensar a educação e a possibilidade de produzir e produzir-se no 'limiar' dos discursos em que se encerram as verdades sobre educação.

Desejamos pensar essa navegação do louco de Foucault de modo afirmativo, assim como ele também pensa o navio como a 'heterotopia por excelência', esses contralugares que contestam e invertem o espaço 'real' em que vivemos (Hara, 2012) e "criam ilusões e mentiras necessárias à vida"(Hara, 2012,pp.47-48). Hara(2012) também pensa um "filósofo singular" como "aquele que entende a filosofia enquanto experimentação, ensaio com o próprio pensamento", aquele que “também se torna um prisioneiro do mar de mil caminhos" (p. 36). Assim, "a errância pelo mar pleno de interpretações" seria como um "ensaio por esses mil caminhos, a experimentação consigo mesmo, visando tanto o abandono das crenças metafísicas enraizadas na subjetividade, quanto a abertura para a constituição de novas formas de viver e de agir" (Hara, 2012, p. 36). Não será, então, quando somos lançados no mar, aprisionados no mar de mil caminhos (de mil interpretações), que o pensamento é forçado a pensar e inventar contralugares?

Frente à questão que desponta, compreendemos que o problema das teorias, ditos e vistos, pelos quais muitas vezes nos apaixonamos, é justamente esse: nos apaixonarmos cegamente por eles, entendendo-os como modelos e não como 'ferramentas' (Foucault, 1991). O desafio, portanto, consiste em colocá-los para vibrar em diferentes situações, explorando desse modo variações que operem rachaduras em suas composições e oportunizem o nascimento de outros modos de pensá-los; ao mesmo tempo, outros modos singulares de pensar-nos e de pensarmos.

Note-se que não há aqui uma perspectiva moral, uma busca por um fim. Apenas o desejo de experimentar outros lugares, a cada vez. Tal exercício que fazemos, de revezamento de teoria e prática, enquanto movimento à produção de saberes que se fazem em meio a capturas e interdições no fazer ensino-pesquisa, requer que não falemos em nome da verdade, mas apenas pelos fragmentos que nos compõem a partir de biografemas.

Sabemos que esse não é um movimento fácil, pois convivemos com as visões de outros tempos e espaços, que coexistem no emaranhado que pulsa na superfície cotidiana que habitamos. Carregamos heranças que muitas vezes não

\footnotetext{
${ }^{6}$ De acordo com Nietzsche (1998), a vida, a partir de Sócrates, passa a ser configurada como expressão de uma estrutura puramente racional, em que os dogmáticos reduzem a pluralidade de perspectivas a um único discurso acerca da verdade.
} 
desejamos carregar, concepções que grudam em nosso corpo, e que, em muitas situações, acabamos por reproduzir, ou vemos reproduzidas por aí. Essas circunscrições vão persistindo e se infiltrando em tessituras atuais, e por vezes nos prendem em concepções que já não dão conta do que vivenciamos, mas, por estarem coladas e aderidas em nós, por vezes não conseguimos nos desvencilhar delas.

Nesse sentido, o que nos cabe? Talvez a resposta esteja em apenas lembrar... Lembrar? Sim... Lembrar que as nossas escolhas não são neutras, elas produzem realidades e modos de vida. Lembrar que as nossas escolhas foram inventadas por alguém... Lembrar que elas são apenas uma das possibilidades imagináveis... E lembrar que infinitas outras possibilidades permanecem aguardando a nossa invenção conforme as exigências e contingências de cada momento.

Esse texto deu-se como um exercício que se propôs a pensar nossos modos de relacionar teoria e prática. Apostamos, assim, no revezamento entre ambas como impulso para encontrar possibilidades outras de fazer pesquisa/docência, ocupados mais em problematizar do que em nos fecharmos em soluções. Apropriamo-nos da filosofia, torcendo alguns conceitos em proveito do pensamento aqui disparado, bem como das experimentações com a arte, e da produção de pesquisas (em universidades distintas) para viabilizar zonas de vizinhança entre teoria $e$ prática, produção de saberes e vida, justamente por compreender a educação enquanto acontecimento.

Em vista disso, o texto emergiu como força em ato de pensar coletivamente, também como meio de produzir diferenças, enquanto vontade de potência do corpo/pensamento que se encoraja a pensar. Por isso mesmo, não tem sentido ser tomado como modelo, ou exemplo a ser seguido, dado que, por dar-se como uma experimentação, já é corpo desfeito; apenas preserva a sensibilidade dos dedos de quem tateia a fim de manter-se em movimento. Tratase mais de um 'obrar' nas brechas (ou mesmo na produção delas), escavando o presente a partir das superfícies sedimentadas, as quais muitas vezes habitamos (em sala de aula, projetos de estágios, produção de dissertações e teses, orientações, etc.), para que possamos, como um dos resultados possíveis em nosso agir cotidiano de pesquisadores/docentes, criar estratégias que façam fugir, gerando outra coisa.

\section{REFERÊNCIAS}

Barthes, R. (2003). Roland Barthes por Roland Barthes. São Paulo: Estação Liberdade.

Boutang, P.-A. (Realizador) (1988-1989). O abecedário de Gilles Deleuze [Entrevista a Giles Deleuze por Claire Parnet] [DVD]. Paris: Éditions Montparnasse.

Corazza, S. M. (2011). A formação do professorpesquisador e a criação pedagógica. Revista da Fundarte, 11, 13-16.

Corazza, S. M. (2013). O que se transcria em educação? Porto Alegre: UFRGS.

Deleuze, G. (1992). Conversações. São Paulo: Ed. 34.

Deleuze, G. (2006). A ilha deserta e outros textos. São Paulo: Iluminuras.

Deleuze, G. (2009). Nietzsche. Lisboa: Edições 70.

Deleuze, G., \& Guattari, F. (2012). Mil platôs 5. São Paulo: Ed. 34.

Deleuze, G. \& Parnet, C. (1998). Diálogos. São Paulo: Editora Escuta.

Deligny, F. (2015) O aracniano e outros textos. São Paulo: n-1 edições.

Foucault, M. (1972). História da loucura. São Paulo: Perspectiva.

Foucault, M. (1991). Ditos e escritos (vol. 2). Rio de Janeiro: Forense Universitária.

Foucault, M. (1997). A arqueologia do saber (5a ed.). Rio de Janeiro: Forence Universitária.

Foucault, M. (2012). Os intelectuais e o poder (Conversa entre Gilles Deleuze e Michel 
Foucault). In M. Foucault, Microfísica do poder (30 reimpressão, pp. 69-78). Rio de Janeiro: Edições Grall.

Gallo, S. (2010). Filosofia da diferença e educação: O revezamento entre teoria e prática. In S. M. Clareto \& A. Ferrari (Orgs.), Foucault, Deleuze e educação (pp. 45-63). Juiz de Fora: Editora UFJF.

Hara, T. (2012). A errância e o mar de mil caminhos. Ensaios sobre a singularidade. São Paulo: Intermeios; Londrina: Kan Editora.

Kastrup, V. (2005). Políticas cognitivas na formação do professor e o problema do devirmestre. Educação \& Sociedade, 26(93), 12731288. Disponível em: http://www.scielo.br/ pdf/es/v26n93/27279.pdf

Kastrup, V. (2007). Flutuações da atenção no processo de criação. In E. Leger, S. Borba, \&W. Kohan (Orgs.), Imagens da imanência, escritos em memória de H. Bérgson (pp. 103-123). Belo Horizonte: Autêntica.

Larrosa, J. (2011). Experiência e alteridade em educação. Reflexão e Ação, 19(2), 4-27. Disponível em: https://online.unisc.br/seer/ index.php/reflex/article/view/2444/1898

Mossi, C. P. (2016). Escritas, leituras, visualidades: Povoamentos para pensar a aula (ou a docência) como zona de pesquisa. Revista Digital do LAV, 9(2), 61-74.

Nietzsche, F. (1998). Genealogia da moral. São Paulo: Companhia das Letras.

Nietzsche, F. (2001). A gaia ciência. São Paulo: Companhia das Letras.

Oliveira, M. O. (2015). Como produzir clarões nas pesquisas em educação? Revista Educação Pública, 24(56), 443-454.
ON ALTERNATIONS BETWEEN THEORY AND PRACTICE: MOVEMENTS THAT ACTIVATE OTHER WAYS OF THINKING Art EDUCATION

\section{Abstract}

This text will approach some experimentations we have developed in higher education with groups of undergraduate and graduate students. Our challenge has been: how to alternate theory and practice in a way that these instances do not happen apart from each other? To do so, we have sought to overlap them so that they happen concomitantly. These experimentations have occurred as elaborations of practice projects, in the classes of the supervised teaching practice, where teacher candidates are responsible for a school group or other. Equally, as far as research procedures are concerned, Master's dissertations and $\mathrm{PhD}$ theses are also operated through this alternation and concomitance. To the accomplishment of this writing, a theoretical-conceptual bibliographic study has been developed with authors aligned with the theoretical basis of the philosophies of difference. Hence, we sought for the depersonalization of authors to speak of a life written by crossings and encounters, i.e. to think life as the very own elaboration of text, a biographematic writing, as Roland Barthes proposes. This way we started composing, with the experienced, the readings, the speeches in the encounters and the visualities, the notes, and through this materiality we wrote this text.

KeY-words: Philosophies of difference; Art teaching; Biographematics; Education 


\section{Alternancias entre la teoría Y LA PRÁCTICA: MOVIMiEntos QUE ACCIONAN OTROS MODOS DE PENSAR LA ENSENANZA DEL ARTE}

\section{RESUMEN}

Este texto abordará algunas experimentaciones que hemos realizado en la enseñanza superior con grupos de graduación y también con grupos de pos-graduación. Nuestro desafío ha sido: ¿Cómo hacer una rotación entre teoría y práctica de modo que esas instancias no se den de formas separadas? Para tanto, hemos buscado sobreponerlas para que ocurran concomitantemente. Esas experimentaciones se han dado en la forma de elaborar los proyectos de pasantía, en las propias clases de pasantía curricular supervisionada, donde los profesores en formación asumen un grupo en la escuela o en otro espacio educativo. Igualmente en lo que se refiere a los procedimientos de hacer investigación, se busca que la disertación y la tesis también sean operadas desde esta rotación y concomitancia. Para la realización de esta escrita se emprendió un estudio teórico-conceptual de perfil bibliográfico con autores afiliados en las bases teóricas de las filosofías de la diferencia. De ese modo, se buscó la despersonalización de los autores para hablar de una vida que es escrita por cruces y encuentros, o sea, pensar la vida como la propia elaboración de un texto, una escrita biografemática, siguiendo la propuesta de Roland Barthes. Así hemos compuesto, con lo vivido, con las lecturas, las hablas en los encuentros y las visualidades, los apuntamientos, y desde esa materialidad es que ensayamos ese texto.

Palabras-Clave: Filosofías de la diferencia; Enseñanza del arte; Biografemática; Educación

\footnotetext{
I Programa de Pós-Graduação em Educação, Universidade Federal de Santa Maria (UFSM), Brasil. ORCID: 0000-0002-50928806

"I Programa de Pós-Graduação em Educação, Universidade Federal de Santa Maria (UFSM), Brasil. ORCID: 0000-0002-30878995

${ }^{\text {III }}$ Programa de Pós-Graduação em Educação, Universidade Federal de Santa Maria (UFSM), Brasil. ORCID: 0000-00033525-9517

Iv Programa de pós-graduação em Educação - Universidade Federal de Santa Maria (UFSM) Brasil. Universidade Estadual de Maringá (UEM) Brasil. ORCID: 0000-0001-6401-5429
} 